\title{
Displacement of the Residual Liver Cavity in Laparoscopic Echinococcectomy
}

\section{Baiyshbek Osumbekovi,2, Murat Chokotaev ${ }^{2}$, Ruslan Osumbekov', Nurdin Mamanov ${ }^{3}$, Zamirbek Arynov ${ }^{4}$, Zhypargul Abdullaeva ${ }^{1,5^{*}}$ (i)}

${ }^{1}$ Science and Research Department, Osh State University, Osh, Kyrgyzstan

${ }^{2}$ Medical Clinic EndoMed, Osh, Kyrgyzstan

${ }^{3}$ Endovideosurgical Center URFA Clinic, Bishkek, Kyrgyzstan

${ }^{4}$ Surgical Disciplines and Traumatology Department, International Medical Faculty, Osh State University, Osh, Kyrgyzstan ${ }^{5}$ Anatomy, Histology and Normal Physiology Department, International Medical Faculty, Osh State University, Osh, Kyrgyzstan Email: *jypar.science@oshsu.kg

How to cite this paper: Osumbekov, B., Chokotaev, M., Osumbekov, R., Mamanov, N., Arynov, Z. and Abdullaeva, Z. (2020) Displacement of the Residual Liver Cavity in Laparoscopic Echinococcectomy. Surgical Science, 11, 281-288.

https://doi.org/10.4236/ss.2020.1110030

Received: September 9, 2020

Accepted: September 27, 2020

Published: September 30, 2020

Copyright $\odot 2020$ by author(s) and Scientific Research Publishing Inc. This work is licensed under the Creative Commons Attribution International License (CC BY 4.0).

http://creativecommons.org/licenses/by/4.0/

\begin{abstract}
Aim: This article aimed to investigate the analysis of various methods for eliminating the residual liver cavity after laparoscopic echinococcectomy in patients. Methods: The authors used the following methods of eliminating the residual cavity: omentoplasty (36.8\%), abdominalization (30\%), drainage of the residual cavity (26.2\%), and a combination of omentoplasty with drainage of the residual cavity (7\%). Results: In the postoperative period, complications occurred in 2 (3.5\%) cases in the form of bile leakage from the residual liver cavity. Conclusions: It is recommended to use abdominalization and omentoplasty when choosing a method for eliminating the residual liver cavity.
\end{abstract}

\section{Keywords}

Echinococcosis of the Liver, Laparoscopic Echinococcectomy, Residual Liver Cavity, Omentoplasty, Abdominalization

\section{Introduction}

Elimination of the residual liver cavity (RLC) as the final stage of echinococcectomy (EE) operation is one of the most controversial and topical issues in the surgical treatment of liver echinococcosis [1] [2] [3] [4]. This is due to the fact, that the results of the treatment of echinococcal hepatic cysts (EHC), which still do not satisfy surgeons depend on the choice of certain operational and technical solutions to eliminate RLC. The etiology of this study including treatment of the 
liver echinococcosis caused by Echinococcus granulosus, transmitted through the intermediate hosts such as dogs, cats and domestic animal feces. Various procedures developed to overcome complications of echinococcosis including external or internal drainage following evacuations and capitonnage with or without omentoplasty [5].

In laparoscopic echinococcectomy (LEE), different authors have proposed various methods for eliminating the residual liver cavity such as radical excision of the fibrous cap (FC) [6] [7]. The partial pericystectomy, omentoplasty, and external drainage of RLC [8], omentoplasty, and external drainage of RLC [9] [10] performed. If the volume of RLC is more than $200 \mathrm{ml}$, a method of vacuum obliteration of the RLC proposed, where a wide silicone tube inserted into the RLC and a negative pressure about 250 mbar created. For the faster obliteration of RLC, the use of the RLC method for RLC vacuum obliteration is provided [10]. For large cysts up to $180 \mathrm{~mm}$, the local application of a hemostatic sponge combined with external drainage of the RLC [11].

Omentoplasty is not recommended by many laparoscopic surgeons, but it is considered a fairly effective way to eliminate RLC. However, obliteration of the cavity with greater omentum previously reported to reduce complications and help to achieve obliteration in laparoscopic procedures [12]. The choice of the method for terminating LEE and eliminating RLC in many aspects depends on the priority of the surgeon, the size, number and location of the liver echinococcectomy, and the nature of complications. Laparoscopic surgeons have not yet finally developed a single, unified view on these issues. The purpose of this article is to analyze the various methods used to eliminate the RLC in the liver echinococcectomy.

\section{Materials and Methods}

This work based on the liver echinococcectomy analysis results in 57 patients with LEE in the Osh Interregional Joint Clinical Hospital. Results from 2010-2017 have been analyzed. The median age of 57 patients was 31 years $(24-50)$. Females predominated $40(70.1 \%)$. Men made up 17 (29.9\%) people. The dimensions of the EHC ranged from 17 to $140 \mathrm{~mm}$. Analysis of the duration before hospitalization shows that the majority of patients suffered from hepatic echinococcosis for more than 2 - 3 years. In 17 (29.8\%) observations, echinococcal hepatic cysts (EHC) complicated by suppuration. In all observed 57 patients, 18 (31.5\%) were operated on at various times before hospitalization in our institution. In $19.3 \%$ of cases, chronic calculous cholecystitis detected, requiring simultaneous surgical correction. Distribution of patients by the degree of anesthetic risk according to the ASA scale: ASA 1 - 47 (82.4\%) patients, ASA 2 - 8 (14\%), ASA 3 - 2 (3.5\%).

The indications for LEE [13] were:

1) EHC type CL, CE1, CE2 with dimensions up to $150 \mathrm{~mm}$;

2) EHC type CE3, CE4, and CE5 of small dimensions (up to 50 - $100 \mathrm{~mm}$ );

3) Localization of EHC in the anterior segments of the liver (S II, III, IVb, V, 
$\mathrm{VI})$;

4) Subcapsular location of the EHC;

5) Absence of cystobiliary fistulas.

For the laparoscopic operation, we used standard endovideosurgical stands from EFA-MEDIKA (St. Petersburg, Russia) and KARL STORZ (Germany). The LEE methodology was generally accepted and included the following steps: isolation of the hydatid cyst with napkins moistened with a germicidal solution; puncture; aspiration; irrigation with germicide ( $30 \% \mathrm{NaCl}$ solution, dekasan); the opening of FC; chitinectomy; argon-plasma treatment and elimination of the RLC.

\section{Statistical Processing Methods}

Statistical processing of the digital material carried out using the program "STATISTICA" Version 6. In the process of statistical analysis, quantitative values are indicated as the statistical mean $(M) \pm$ standard deviation (SD). Statistical processing of digital data in determining the reliability of differences in the quantitative values of the research results carried out using the Student's t-test. Differences were considered statistically significant if the probability of a possible error was $\mathrm{p}$ (significance level) $<0.05$. The number of omentoplasty, omentoplasty with drainage of residual liver cavity (RLC), abdominalization, drainage of RLC, number of patients with treatment results were collected as variables.

\section{Results and Discussions}

The following methods of the RLC elimination used: omentoplasty, abdominalization, river cavity drainage, and a combination of omentoplasty with the liver cavity drainage (Table 1).

As can be seen from Table 1, omentoplasty is most often used to eliminate the RLC (21 patients, 36.8\%). In addition, in another 4 (7\%) cases, omentoplasty was combined with RLC drainage. The second most frequently used was abdominization of the RLC, which was used in 17 (30\%) patients with echinococcal cysts of the liver. Only the RLC drainage without RLC elimination performed in 15 (26.2\%) patients.

Table 1. Ways to eliminate the residual liver cavity (RLC) with echinococcectomy (EE) laparoscopic method.

\begin{tabular}{ccc}
\hline \multirow{2}{*}{ Methods for eliminating RLC } & \multicolumn{2}{l}{ Number of observations } \\
\cline { 2 - 3 } & Abs. & $\%(\mathbf{M} \pm$ SD) \\
\hline Omentoplasty & 21 & $36.8 \pm 6.3$ \\
Abdominalization & 17 & $30 \pm 6.0$ \\
Drainage of RLC & 15 & $26.2 \pm 5.8$ \\
Omentoplasty with drainage of RLC & 4 & $7 \pm 3.3$ \\
Total & 57 & 100 \\
\hline
\end{tabular}


Table 2 shows the chronological dynamics of various methods used for eliminating the RLC after LEE, which also shows that omentoplasty (on 25 patients) and abdominalization (on 17 patients) were preferred.

\subsection{Omentoplasty}

Omentoplasty in this work was performed by tamponing the RLC with a flap of the greater omentum, which was fixed to the edges of the FC by clipping ( 6 patients) or with separate 2 - 3 interrupted sutures (19 patients) as shown in Figure 1.

Indications for this method of RLC elimination were the deep location of the EHC $(\mathrm{n}=4)$, the diameter size of the cyst $60-90 \mathrm{~mm}(\mathrm{n}=8)$, and solitary cysts $(n=7)$. This method was technically unsuccessful in patients with poor development of the greater omentum, with large and multiple EHCs, pronounced adhesive process. In 4 patients with festering EHC, omentoplasty was supplemented with RLC drainage. Such tactics, to a certain extent, contradict the generally accepted principles, but our results allow us to believe that, at small sizes of the EHC, sealing the RLC with an oil seal is permissible as in the following clinical case.

Patient 28 years old, hospitalized with complaints of dull pain and heaviness in the right hypochondrium, dry mouth, impaired appetite. 3 years ago, she

Table 2. Chronological dynamics of methods used for eliminating the residual liver cavity (RLC) in the case of the liver echinococcectomy (LEE).

\begin{tabular}{cccccccccc}
\hline $\begin{array}{c}\text { Methods for } \\
\text { eliminating RLC }\end{array}$ & 2010 & 2011 & 2012 & 2013 & 2014 & 2015 & 2016 & 2017 \\
\cline { 2 - 8 } & 2 & 1 & - & 2 & 4 & 1 & 6 & 1 \\
\hline $\begin{array}{c}\text { Abdominalization } \\
\text { Omentoplasty }\end{array}$ & 1 & - & 4 & 2 & 3 & 4 & 5 & 2 \\
Drainage of RLC & 2 & 1 & 4 & 2 & 2 & - & 2 & 2 \\
$\begin{array}{c}\text { Omentoplasty with } \\
\text { drainage of RLC }\end{array}$ & - & - & - & - & 3 & - & - & 1 \\
Total & 5 & 2 & 8 & 6 & 12 & 5 & 13 & 6 \\
\hline
\end{tabular}

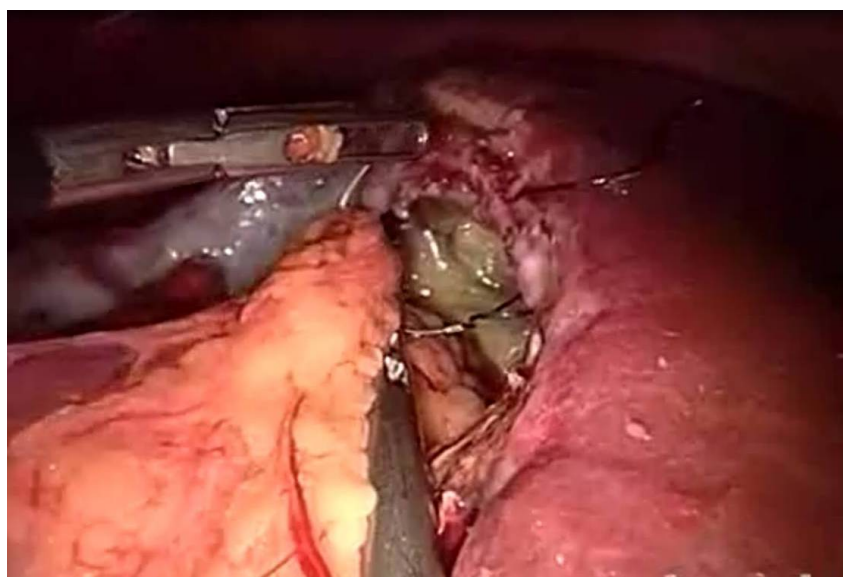

Figure 1. Omentoplasty by suturing the omentum to the FC edge. 
underwent a cesarean section. Objective status: the general condition is relatively satisfactory. The skin color is normal. Breathing is not disturbed, carried out on both sides, vesicular, with no wheezing $(110 / 70 \mathrm{mmHg}$, pulse 86 beats per minute). The abdomen is soft on palpation, moderate pain in the right hypochondrium was determined. There were no symptoms of peritoneal irritation. The liver and spleen are not palpable. Physiological arrangements are not disturbed. No liver enlargement observed by ultrasound, the right lobe was homogeneous, without focal changes, the usual acoustic density. In the left lobe of the liver, and echinococcal cyst with inhomogeneous contents of $58 \mathrm{~mm}$ in size observed. Intrahepatic bile ducts and venous networks are not dilated.

The operation of the LEE revealed that echinococcal cyst was located in the left lobe of the liver in close proximity to the falciform ligament. The cyst was isolated with gauze napkins moistened with decasan, puncture, aspiration, irrigation of the cyst cavity, the opening of the FC, chitinectomy in the endocontainer. The contents of the cyst are purulent, the chitinous membrane with signs of purulent fusion, and easily breaks when captured by grasses. The RLC was repeatedly washed with a heated furacillin solution, after which the antiparasitic treatment of the RLC was performed with a hypertonic solution (30\%) of sodium chloride. Endovideocystoscopy observed no biliary fistulas. The RLC is filled with a flap of the greater omentum, which is fixed by clipping to the edges of the FC. Drainage of the subhepatic space, desufflation, and suturing of trocar wounds performed. On the $3^{\text {rd }}$ day after the operation, drainage was removed and the patient was discharged home. With a control ultrasound in a month, an echogenic focus of an inhomogeneous structure with uneven contours is determined in the left lobe of the liver no residual cavity observed.

\subsection{Abdominisation}

In $17(30 \%)$ cases of the elimination, the RLC in LEE was performed by abdominisation, which consisted of the maximum excision of the free edges of the FC and leaving the cavity open (Figure 2). The main indications for this method are subcapsular localization of the EHC with a noticeable elevation above the liver

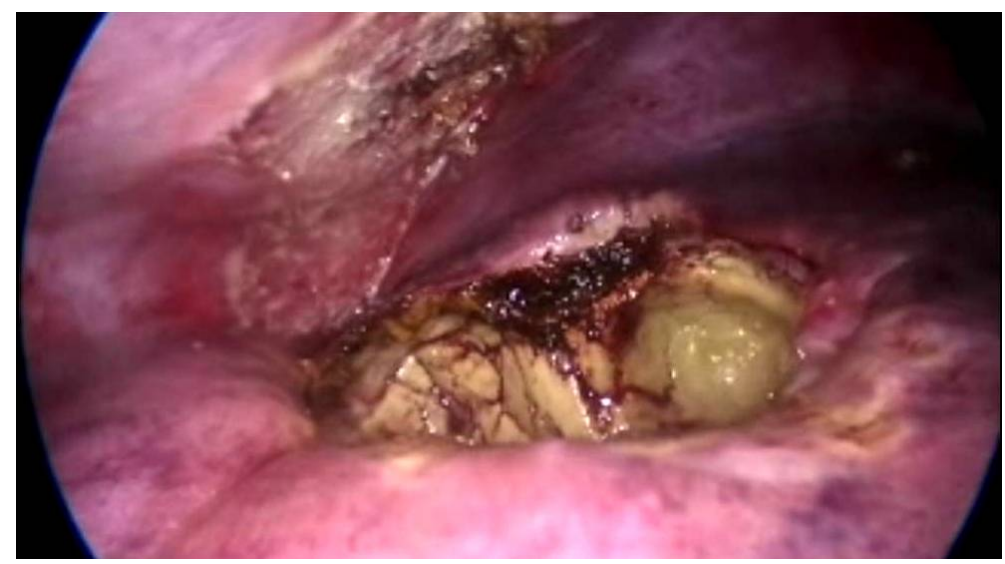

Figure 2. Adbominisation of the RLC. 
surface and the absence of infectious complications (suppuration). The dimensions of the EHC did not play a significant role in our practice, and abdominization was applied both for small and large EHC sizes.

The wider introduction of the method of abdominalization of RLC facilitated by the use of endovideocystoscopy, which allows endovisual assessment of the condition of the RLC wall, excluding the presence of suppuration and cystobiliary fistulas. This method can be used not only for solitary, but also for multiple EHCs, when omentoplasty is not applicable, or it can be combined with other methods for eliminating RLC. Subsequently, after evaluating the immediate and long-term results of the LEE, the method of abdominalization of the RLC in our practice became preferred in the LEE methodology.

In $15(26.3 \%)$ patients, RLC was drained with one perforated drainage. 8 (53.3\%) patients had EHCs that were suppurating. EHC suppuration excluded the possibility of RLC elimination, which was fraught with a high risk of developing purulent-inflammatory complications of RLC. As mentioned above, there were observations when omentoplasty and abdominalization used for suppurative EHCs.

In both groups of patients, there were no specific complications such as EHC perforation with the development of anaphylactic shock and intra-abdominal dissemination of the parasite elements.

In the postoperative period, complications occurred in $2(3.5 \%)$ cases in the form of bile leakage from RLC, which independently ceased on days 12 and 20 after the operation. The daily flow rate of bile through drainage averaged 60-80 $\mathrm{ml}$. Control ultrasound showed no free fluid in the abdominal cavity; the drains were in the RLC. And in the remaining 55 (96.5\%) patients after LEE, there was no bile leakage and the duration of RLC drainage averaged $3.9 \pm 2.5$ days. The intensity of postoperative pain after LEE was minimal, $3.3 \pm 1.2 \mathrm{~mm}$, and did not require the use of narcotic analgesics.

It should be noted the early activation of patients after laparoscopic surgery. The patients became more active already, on average, $5.3 \pm 1.6$ hours after the operation. After LEE, the intestinal passage was restored $11.3 \pm 3.4$ hours after the operation. All of these indicators affected the duration of inpatient stay and the duration of labor rehabilitation of patients. The average hospital stay was 6.0 \pm 3.1 bed-days.

When analyzing postoperative complications according to the Clavien-Dindo classification, grade I complications were observed in one (1.7\%) patient in the form of bile leakage with a daily bile flow rate of up to $60 \mathrm{ml} /$ day, which closed on its own on day 12 after LEE. Complications of the II degree also occurred in one (1.7\%) patient (bile leakage from RLC), which led to an increase in the duration of the patient's stay in the hospital. Complications of III, IV, and V degree of complications according to Clavien-Dindo not observed. Long-term results were studied in all patients and presented in Table 3.

Analysis of long-term results of operated patients showed that most patients (86\%) had a good result and $14 \%$ had a satisfactory result. There were no relapses 
Table 3. Long-term results of LEE.

\begin{tabular}{ccc}
\hline \multirow{2}{*}{ Results } & \multicolumn{2}{c}{ Number of patients $(\mathbf{n}=\mathbf{5 7})$} \\
\cline { 2 - 3 } & Abs. & $\%(\mathbf{M} \pm \mathbf{S D})$ \\
\hline Good & 49 & $86.0 \pm 3.4$ \\
Satisfactory & 8 & $14.0 \pm 3.4$ \\
Unsaticfactory & - & - \\
\hline
\end{tabular}

of echinococcosis and other conditions requiring surgical treatment. In 8 (14\%) patients with a satisfactory result in the long-term postoperative period, RLCs up to $2-4 \mathrm{~cm}$ in size with homogeneous echo-negative contents, which clinically did not manifest themselves, were found sonographically.

In a dynamic study, within 4 - 6 months, complete involution of the RLC occurred with the formation of an irregular shape of an echo-dense fibrous focus. LEE in these 8 patients was completed by drainage of RLC without its elimination. The reason for choosing RLC drainage was the large size of the hydatid hepatic cyst ( 3 patients), as well as in the first cases of using laparoscopy in the surgical treatment of EHC (5 patients).

\section{Conclusion}

Thus, the analysis of the obtained results of the LEE allows making many recommendations. In the case of LEE, the elimination of RLC is recommended to be performed by the abdominal method (maximum excision of the free edges of the FC and leaving the cavity open), indications for which are subcapsular localization of the cyst and the absence of infectious complications (suppuration). Abdominalization of RLC is applicable for both small and large EHC sizes. In the latter case, this method of eliminating RLC can be combined with external drainage. Omentoplasty of the RLC indicated for deep EHCs, cyst with diameter size $60-90 \mathrm{~mm}$, and solitary cysts. This method is contraindicated in patients with poor development of the omentum, with large (more than $90 \mathrm{~mm}$ ) and multiple EHC, pronounced adhesive process.

\section{Conflicts of Interest}

The authors declare no conflicts of interest regarding the publication of this paper.

\section{References}

[1] Panteleev, V., Nartaylakov, M., Airat Mustafin, A., Abdeyev, R., Salimgareyev, I., Samorodov, A. and Musharapov, D. (2019) Surgical Treatment of Liver Echinococcosis and Alveococcosis. Le Infezioni in Medicina, 4, 422-428.

[2] Kowalczyk, M., Kurpiewski, W., Zieliński, E., Zadrożny, D., Klepacki, Ł., Juśkiewicz, W., Lasocki, J., Dyśko, Ł., Batia, K. and Pesta, W. (2019) A Rare Case of the Simultaneous Location of Echinococcus Multilocularis in the Liver and the Head of the Pancreas: Case Report Analysis and Review of Literature. BMC Infectious Diseases, 
19, Article No. 661. https://doi.org/10.1186/s12879-019-4274-y

[3] Bayrak, M. and Altıntas, Y. (2019) Current Approaches in the Surgical Treatment of Liver Hydatid Disease: Single Center Experience. BMC Surgery, 19, Article No. 95. https://doi.org/10.1186/s12893-019-0553-1

[4] Sharma, B.C., Reddy, R.S. and Garg, V. (2012) Endoscopic Management of Hepatic Hydatid Cyst with Biliary Communication. Digestive Endoscopy. Official Journal of the Japan Gastroenterological Endoscopy Society, 24, 267-270. https://doi.org/10.1111/j.1443-1661.2011.01225.x

[5] Sözen, S., Emir, S., Tükenmez, M. and Topuz, O. (2011) The Results of Surgical Treatment for Hepatic Hydatid Disease. Hippokratia, 15, 327-329.

[6] Marks, J., Mouiel, J., Katkhouda, N., Gugenheim, J. and Fabiani, P. (1998) Laparoscopic Liver Surgery. A Report on 28 Patients. Surgical Endoscopy, 12, 331-334. https://doi.org/10.1007/s004649900664

[7] Manterola, C., Fernández, O., Muñoz, S., Vial, M., Losada, H., Carrasco, R., Bello, N. and Barroso, M. (2002) Laparoscopic Pericystectomy for Liver Hydatid Cysts. Surgical Endoscopy and Other Interventional Techniques, 16, 521-524. https://doi.org/10.1007/s00464-001-8125-7

[8] Bickel, A., Loberant, N., Singer-Jordan, J., Goldfeld, M., Daud, G. and Eitan, A. (2001) The Laparoscopic Approach to Abdominal Hydatid Cysts: A Prospective Nonselective Study Using the Isolated Hypobaric Technique. Archives of Surgery, 136, 789-795. https://doi.org/10.1001/archsurg.136.7.789

[9] Khoury, G., Abiad, F., Geagea, T., Nabout, G. and Jabbour, S. (2000) Laparoscopic Treatment of Hydatid Cysts of the Liver and Spleen. Surgical Endoscopy, 14, 243-245. https://doi.org/10.1007/s004640000048

[10] Saglam, A. (1996) Laparoscopic Treatment of Liver Hydatid Cysts. Surgical Laparoscopy and Endoscopy, 6, 16-21.

[11] Zubarev, P.N., Ivanov, S.A. and Ignatovich, I.G. (2001) New Methods of Surgical Treatment of Echinococcal Cysts of the Liver. Vestnik hirurgii. Saint Petersburg, 6, 75-78.

[12] Altinli, E., Saribeyoglu, K., Pekmezci, S., Uras, C., Tasçi, H. and Akçal, T. (2002) An Effective Omentoplasty Technique in Laparoscopic Surgery for Hydatid Disease of the Liver. JSLS: Journal of the Society of Laparoendoscopic Surgeons, 6, 323-326.

[13] Eckert, J. and Deplazes, P. (2004) Biological, Epidemiological, and Clinical Aspects of Echinococcosis, a Zoonosis of Increasing Concern. Clinical Microbiology Reviews, 17, 107-135. https://doi.org/10.1128/CMR.17.1.107-135.2004 